\title{
POSTUR KERJA DENGAN KELUHAN MUSCULOSKELETAL DISORDERS PADA PEKERJA MANUAL HANDLING BAGIAN ROLLING MILL
}

\author{
Nurdian Evadarianto, Endang Dwiyanti \\ Departemen Keselamatan dan Kesehatan Kerja \\ Fakultas Kesehatan Masyarakat Universitas Airlangga \\ Email: ariexkey@gmail.com
}

\begin{abstract}
In the production process, there are many activities use human power, such as in material processing, packing and transportation of production manually or manual handling. If the procedure not done the right way, it will lead to disruption in the system of muscles, bones, tendons, and nerves called with musculoskeletal disorders. This study aimed to determine the relationship between work posture and the incidence of musculoskeletal disorders. This research was an analytic observational with cross sectional approach. Total sample is used to take the sampling amount to 15 people. Techniques of collecting data through observation and questionnaires. The posture workers were measured by using REBA valuation methods and the incidence of complaints of musculoskeletal disorders (MSDs) were measured by filling sheets of Nordic Body Map (NBM). Data were analyzed using Spearman correlation test. The results showed that there were $73.34 \%$ (11 people) work posture workers with very high category, 73.34\% (11 people) workers experienced MSDs complaint with the medium category. Spearman correlation coefficient value was 0.770 , indicated there was a very strong correlation between work posture with MSDs complaint. The posture of work that was not ergonomically or not nature caused incident of musculoskeletal disorders. When the work posture got worse, the musculoskeletal complaint increased. The company made redesign the layout, one of them by avoiding the raised floor. Perform routine surveillance on the activities that have high risk to cause injury, and hold regular exercise activities once a week.
\end{abstract}

Keywords: Manual Handling Workers, Musculoskeletal Disorders, work posture

\begin{abstract}
ABSTRAK
Dalam proses produksi, banyak kegiatan yang menggunakan tenaga manusia, misalnya dalam proses pengolahan bahan, pengepakan dan pengangkutan hasil produksi secara manual atau manual handling. Hal tersebut apabila tidak dilakukan dengan cara yang benar, maka akan mengakibatkan gangguan pada system otot, tulang, tendon, dan syaraf disebut dengan musculoskeletal disorders. Penelitian ini bertujuan untuk mengetahui keeratan hubungan antara postur kerja dengan kejadian keluhan musculoskeletal disorders. Penelitian ini bersifat analitik observasional dengan pendekatan cross sectional, sampel penelitian ini menggunakan total populasi pekerja yang berjumlah 15 orang. Teknik pengumpulan data dengan observasi dan pengisian kuesioner. Postur pekerja diukur menggunakan metode penilaian REBA, serta kejadian keluhan musculoskeletal disorders (MSDs) diukur melalui pengisian lembar Nordic Body Map (NBM). Data dianalisis menggunakan uji korelasi spearman. Hasil penelitian ini yaitu sebanyak 73,34\% (11 orang) postur kerja pekerja dengan kategori sangat tinggi, 73,34\% (11 orang) pekerja mengalami keluhan MSDs dengan kategori sedang. Nilai koefisien korelasi spearman sebesar 0,770 yang artinya ada hubungan yang sangat kuat antara postur kerja dengan keluhan MSDs. Postur kerja yang tidak ergonomi atau tidak alamiah dapat menyebabkan kejadian keluhan MSDs. Semakin buruk postur kerja, maka keluhan musculoskeletal semakin besar. Pihak perusahaan melakukan redesign layout, salah satunya dengan menghindarkan lantai bertingkat. Melakukan pengawasan rutin pada kegiatan yang berisiko terjadinya cidera, dan mengadakan secara rutin kegiatan olah raga satu kali dalam seminggu.
\end{abstract}

Kata kunci: Musculoskeletal Disorders, pekerja manual handling, postur kerja

\section{PENDAHULUAN}

Kemajuan teknologi yang semakin meningkat membuat proses produksi untuk menghasilkan barang atau jasa semakin banyak, baik yang dilakukan dengan mesin ataupun dengan tenaga manusia atau secara manual. Proses produksi di sebuah perusahaan masih banyak yang menggunakan atau melibatkan manusia dalam proses pekerjaannya dengan menggunakan alat-alat manual. Hal tersebut membuat peran manusia atau pekerja hingga pada saat ini masih menjadi hal yang paling penting dan utama dalam menghasilkan suatu produksi. Sehingga pada pekerjaan yang aktivitasnya masih membutuhkan penanganan secara manual atau 
bisa disebut manual handling. Manusia dituntut untuk mempunyai kemampuan lebih agar bisa menghasilkan peran sesuai dengan yang diinginkan, khususnya pada tulang dan otot karena tulang dan otot merupakan dua hal yang sangat penting bagi manusia atau pekerja dalam bekerja. Manusia mempunyai kemampuan dan keterbatasan baik fisik dan non fisik dan sering ditemukan kasus yang berhubungan dengan tulang dan otot atau disebut musculoskeletal.

Banyak kegiatan yang menggunakan tenaga manusia pada proses produksi, misalnya dalam proses pembuatan bahan, pengepakan dan pengangkutan hasil produksi. Pekerjaan tersebut sangat dipengaruhi oleh beban dari benda yang diangkut, cara mengangkat, posisi mengangkat, jarak tempuh mengangkat, dan frekuensi mengangkat. Apabila mengangkat atau memindahkan barang ini dilakukan dengan cara yang tidak benar, maka akan mengakibatkan rasa sakit, terutama pada punggung maupun anggota badan yang lainnya. Dalam ilmu ergonomi, gangguan atau keluhan yang berhubungan dengan sistem otot dan tulang belakang disebut dengan musculoskeletal disorders (MSDs).

Tarwaka (2004), menjelaskan bahwa musculoskeletal disorders (MSDs) yaitu keluhan yang terjadi pada bagian-bagian otot skeletal yang dirasakan oleh seseorang mulai dari adanya keluhan yang sangat ringan sampai keluhan sangat sakit. Keluhan musculoskeletal disorders (MSDs) yang sering terjadi pada pekerja industri adalah nyeri pergelangan tangan, nyeri leher, nyeri pada punggung serta nyeri pada siku dan kaki. Jika otot pada bagian tubuh tersebut menerima beban statis secara terus menerus dan berulang dalam waktu yang sangat lama akan menimbulkan keluhan berupa kerusakan pada tendon, ligamen dan sendi.

Tarwaka dkk (2004), menerangkan bahwa sikap kerja yang tidak ergonomi, pergerakan otot yang berlebihan, dan aktivitas yang berulang merupakan faktor pekerjaan yang dapat menyebabkan terjadinya keluhan MSDs. Selain itu, faktor lain yang dapat menyebabkan MSDs yaitu getaran, tekanan dan makroklimat dikategorikan sebagai penyebab sekunder dan apabila terjadi membentuk kombinasi atau secara bersamaan antara faktor tersebut, maka akan meningkatkan risiko terjadinya keluhan MSDs. Jenis kelamin, kekuatan fisik, umur, kebiasaan merokok dan atropometri menurut para ahli juga dapat mempengaruhi risiko terjadinya keluhan musculoskeletal disorders atau keluhan otot skeletal.
Beberapa penelitian menunjukkan bahwa MSDs dapat terjadi karena kombinasi berbagai faktor. Menurut Kuntodi (2008) dalam Bukhori (2010), menyimpulkan bahwa gangguan MSDs dapat terjadi oleh beberapa faktor risiko yang dapat memberikan kontribusi, dan dikategorikan dalam tiga kategori yaitu faktor individu yaitu umur, jenis kelamin, lama bekerja, dan antropometri, faktor pekerjaan yaitu faktor yang berasal dari pekerjaan itu sendiri termasuk postur kerja, gerakan repetitive, penggunaan tenaga, dan karakteristik objek, dan faktor lingkungan kerja terdiri dari vibrasi makroklimat dan pencahayaan.

Keluhan musculoskeletal disorders (MSDs) jika tidak segera diatasi atau dilakukan penanganan segera akan mengganggu konsentrasi dalam bekerja, menyebabkan kelelahan dan pada akhirnya akan menurunkan produktivitas. Dampak yang diakibatkan oleh musculoskeletal disorders (MSDs) pada aspek produksi yaitu berkurangnya output, kerusakan material produk yang hasil akhirnya mengakibatkan tidak terpenuhinya deadline produksi serta pelayanan yang tidak memuaskan. Selain itu, biaya yang ditimbulkan akibat absensi atau tidak masuknya pekerja akan menimbulkan penurunan keuntungan. Hal ini disebabkan oleh pengeluaran biaya pelatihan karyawan baru untuk menggantikan karyawan lama yang sakit serta biaya untuk menyewa jasa konsultan dan agen lainnya (Bukhori, 2010).

International Labour Organization (2013), dalam program pencegahan penyakit akibat kerja menjelaskan bahwa Musculoskeletal disorders termasuk carpal tunnel syndrome, 59\% dari semua catatan penyakit yang ditemukan pada tahun 2005 di negara Eropa. Laporan Komisi Pengawas Eropa menghitung kasus musculoskeletal disorders menyebabkan 49,9\% ketidakhadiran kerja lebih dari tiga hari dan $60 \%$ kasus ketidakmampuan permanen dalam bekerja. Pada tahun 2010 di Argentina dilaporkan sebanyak 22.013 kasus dari penyakit akibat kerja, dengan musculoskeletal disorders merupakan kejadian yang paling sering terjadi. Musculoskeletal disorders di Korea mengalami peningkatan yang sangat tinggi dari 1.634 pada tahun 2001 menjadi 5.502 pada tahun 2010 (Asni, 2014) .

Hasil studi Departemen Kesehatan dalam profil masalah kesehatan di Indonesia tahun 2005 menunjukkan bahwa sekitar $40,5 \%$ penyakit yang diderita pekerja berhubungan dengan pekerjaannya. Gangguan yang dialami pada 9.482 pekerja di 12 
kabupaten/kota di Indonesia umumnya berupa penyakit MSDs (16\%), kardiovaskuler (8\%), gangguan saraf $(5 \%)$, gangguan pernapasan $(3 \%)$, dan gangguan THT (1,5\%) (Sumiati, 2007), serta di tahun 2010 didapatkan sebanyak 168.768 jumlah kunjungan rumah sakit terbanyak ke dua setelah penyakit infeksi saluran pernapasan bagian atas. Data dari Puskesmas Rumbio Jaya (2011), dalam pencatatannya menyebutkan terdapat 10 kasus penyakit pada pekerja informal yang terdiri dari penyakit gangguan sendi dan musculoskeletal, serta di posisi kedua dengan jumlah kasus 30 dari 146 kasus penyakit yang ada. Hal tersebut dapat menyebabkan masalah kecacatan seperti dislokasi tulang dan sendi.

Hendra (2009), pada penelitiannya terkait dengan keluhan musculoskeletal disorders pada pekerja permanen kelapa sawit, dijelaskan bahwa dari 117 permanen, terjadi keluhan pada punggung bawah dan keluhan pada bagian leher terbanyak dikeluhkan oleh 98 pekerja, dan keluhan pada bahu kanan, pergelangan tangan kanan dan kiri yang dirasakan oleh 95 pekerja, serta keluhan bagian pantat yang paling sedikit yaitu sebanyak 67 pekerja. Postur tubuh, umur, dan masa kerja merupakan faktor risiko yang dapat menyebabkan adanya keluhan musculoskeletal disorders. Dampak musculoskeletal disorders menyebabkan banyak atau hampir sebagian besar pekerjaan terganggu $(97,4 \%)$ dan sebagian kecil menjadi tidak bisa bekerja $(2,6 \%)$.

Berdasarkan hasil penelitian Putri dkk (2013) menunjukkan bahwa dari 42 responden, terjadi sebanyak 26 responden $(61,9 \%)$ postur kerja pada posisi kerja duduk menyebabkan angka kejadian LBP (low back pain) pada pekerja pembersih kulit bawang di UD Bawang Lanang Kelurahan Iringmulyo Kota Metro sebesar 83,3\%.

Upaya pencegahan dan meminimalisasi timbulnya MSDs sangat diperlukan di lingkungan kerja. Pencegahan terhadap MSDs akan memperoleh manfaat berupa penghematan biaya, meningkatkan produktivitas dan kualitas kerja, mengurangi terjadinya kecelakaan kerja, serta meningkatkan kesehatan, kesejahteraan dan kepuasan kerja bagi karyawan.

Berdasarkan survei awal, dengan menggunakan teknik wawancara dengan salah satu pekerja di bagian Rolling Mill didapatkan keluhan dari pekerja adanya keluhan nyeri otot yang dialami oleh pekerja, dan melalui teknik observasi, pekerja di bagian Rolling Mill menggunakan pelindung pinggang dan perut seperti sabuk yang lebar untuk melindungi pada saat pekerja dalam proses pengangkatan barang, selain itu dari data di tahun 2015 yang di dapat dari klinik pengobatan yang ada di PT Ispat Indo didapatkan bahwa dari 30 diagnosa penyakit terdapat diagnosa myalgia dan muscle spam/LBP yang merupakan jenis keluhan Musculoskeletal Disorders dengan total 199 lebih banyak dari pada diagnosa penyakit lainnya. Peneliti tertarik melakukan penelitian mengenai keeratan hubungan antara postur kerja dengan kejadian keluhan Musculoskeletal Disorders (MSDs) pada pekerja bagian Rolling Mill di PT Ispat Indo Sidoarjo.

\section{METODE}

Penelitian dilaksanakan di PT Ispat Indo Sidoarjo pada bulan Agustus 2016 sampai September 2016. Penelitian ini merupakan penelitian analitik observasional untuk menganalisis hubungan antar variabel dengan menggunakan desain penelitian cross sectional, karena setiap variabel diamati pada waktu yang bersamaan. Besar sample yang diambil dalam penelitian ini menggunakan seluruh total populasi pekerja bagian Rolling Mill di PT Ispat Indo Sidoarjo yang berjumlah 15 orang.

Analisis data pada penelitian ini dilakukan untuk menganalisis hubungan antara postur kerja dengan kejadian keluhan Musculoskeletal Disorders (MSDs) pada pekerja dengan menggunakan uji kolerasi dari spearman

\section{HASIL}

\section{Gambaran Perusahaan}

PT. Ispat Indo adalah perusahaan yang berbentuk PMA (penanaman modal asing). PT. Ispat Indo merupakan perusahaan baja terbesar kedua di Indonesia setelah Krakatau Steel (perusahaan milik pemerintah) dan terbesar ke 4 di dunia.

PT. Ispat Indo Sidoarjo didirikan pada tahun 1975 berlokasi di desa Kedungturi, Taman, Sidoarjo. Pada mulanya PT. Ispat Indo hanya menghasilkan coil (kawat baja) dari satu line, kemudian karena pesatnya perkembangan teknologi maka PT. Ispat Indo menambah jumlah produksinya dengan jalan membangun satu line lagi.

Proses produksinya terdiri dari 2 tahap yaitu Steel Melting Shop dan Rolling Mill. Steel melting merupakan proses peleburan besi-besi tua (scrap). Scrap ini diperoleh sebagian besar secara impor dan sebagian lokal yang akan ditaruh di area 
Logistic untuk dipilah-pilah. Proses selanjutnya dilakukan di area Rolling Mill. Billet yang telah di cetak kemudian dipanaskan ulang di BRF (Billet Reheating Furnace). Tujuan dari pemanasan ulang ini adalah untuk memudahkan dalam pemrosesan kembali menjadi wire rod. PT Ispat Indo memiliki 2 line untuk mencetak wire rod yaitu line $\mathrm{A}$ dan line $\mathrm{B}$. Dalam laporan ini hanya dibahas line A saja karena line $\mathrm{A}$ adalah line yang paling produktif saat ini, dan produksinya lebih kompleks dari pada line B. Pada line A terbagi atas empat area produksi, yang terdiri dari: Billet Reheating Furnace area, Mill Equipment area, Collection area dan Finishing area.

\section{Identifikasi Faktor Postur Kerja}

Mengidentifikasi postur kerja dilakukan pengamatan selama 2 kali setiap pekerja atau responden, selama satu shift kerja dari jam 07.00 WIB sampai jam 15.00 WIB, dengan menggunakan metode penilaian REBA (Rapid Entire Body Assessment). Pengukuran dilakukan ketika pekerja melakukan aktivitas pekerjaannya di bagian Rolling Mill PT Ispat Indo Sidoarjo. Menurut Sue Hignett dan Lynn Mc Atamney dalam Tarwaka 2010, disebutkan bahwa pengukuran REBA (Rapid Entire Body Assessment) dilakukan pada anggota tubuh bagian atas seperti lengan, lengan bawah, dan pergelangan tangan, serta badan, leher dan kaki. Selain itu metode ini juga melibatkan faktor beban, jenis pegangan dan jenis aktivitas otot dalam penilaiannya, maka didapatkan hasil pada Tabel 1 .

Pada Tabel 1 tersebut dapat dilihat bahwa sebagian besar pekerja berisiko sangat tinggi yaitu sebanyak 11 Orang $(73,34 \%)$, yaitu pada Billet Reheating Furnace (BRF) dan Mill Equipment Area.

\section{Identifikasi Keluhan Musculoskeletal Disorders (MSDs)}

Mengukur keluhan musculoskeletal disorders (MSDs) yang dirasakan oleh pekerja, penulis atau peneliti menggunakan lembar wawancara untuk mengetahui ada tidaknya keluhan nyeri. Untuk menentukan tingkat keluhan nyeri yang dirasakan para pekerja, peneliti menggunakan lembar Nordic Body Map (NBM) yang terdiri dari 28 bagian tubuh. Dalam metode penskoran menggunakan NBM tersebut, terdapat 4 kategori skor untuk menilai tingkat keluhan yang dirasakan oleh pekerja pada bagian tubuhnya yaitu skor 1 (tidak sakit), skor 2 (agak sakit), skor 3 (sakit), dan skor 4 (sangat sakit). Semua skor dicatat lalu dijumlahkan untuk mendapatkan hasil akhir skor yang akan digunakan untuk menentukan tingkat risiko keluhan Musculoskeletal Disorders (MSDs) yang dirasakan oleh pekerja. Pada pekerja didasarkan pada ada

Tabel 1. Distribusi Frekuensi Postur Kerja pada Bagian Rolling Mill di PT Ispat Indo Sidoarjo

\begin{tabular}{|c|c|c|c|c|}
\hline Bagian & Skor Postur Kerja & Tingkat Risiko & Jumlah & Persentase \\
\hline \multirow{2}{*}{ Billet Reheating Furnace (BRF) } & 11 & Sangat tinggi & \multirow{2}{*}{2} & \multirow{2}{*}{$13,33 \%$} \\
\hline & 11 & Sangat tinggi & & \\
\hline \multirow{9}{*}{ Mill Equipment Area } & 11 & Sangat tinggi & \multirow{9}{*}{9} & \multirow{9}{*}{$60.01 \%$} \\
\hline & 12 & Sangat tinggi & & \\
\hline & 11 & Sangat tinggi & & \\
\hline & 12 & Sangat tinggi & & \\
\hline & 13 & Sangat tinggi & & \\
\hline & 12 & Sangat tinggi & & \\
\hline & 13 & Sangat tinggi & & \\
\hline & 11 & Sangat tinggi & & \\
\hline & 12 & Sangat tinggi & & \\
\hline \multirow{2}{*}{ Collection Area } & 6 & Sedang & \multirow{2}{*}{2} & \multirow{2}{*}{$13,33 \%$} \\
\hline & 5 & Sedang & & \\
\hline \multirow{2}{*}{ Finishing } & 6 & Sedang & \multirow{2}{*}{2} & \multirow{2}{*}{$13,33 \%$} \\
\hline & 6 & Sedang & & \\
\hline & & & 15 & $100 \%$ \\
\hline
\end{tabular}


Tabel 2. Distribusi Frekuensi Musculoskeletal Disorders (MSDs) pada Bagian Roling Mill di PT Ispat Indo Sidoarjo

\begin{tabular}{|c|c|c|c|c|}
\hline Bagian & Skor MSDs & Keluhan MSDs & Jumlah & Presentase \\
\hline \multirow{2}{*}{ Billet Reheating Furnance (BRF) } & 52 & Sedang & \multirow{2}{*}{2} & \multirow{2}{*}{$13,33 \%$} \\
\hline & 53 & Sedang & & \\
\hline \multirow{9}{*}{ Mill Equipment Area } & 51 & Sedang & \multirow{9}{*}{9} & \multirow{9}{*}{$60.01 \%$} \\
\hline & 52 & Sedang & & \\
\hline & 50 & Sedang & & \\
\hline & 51 & Sedang & & \\
\hline & 52 & Sedang & & \\
\hline & 53 & Sedang & & \\
\hline & 54 & Sedang & & \\
\hline & 52 & Sedang & & \\
\hline & 52 & Sedang & & \\
\hline \multirow{2}{*}{ Collection Area } & 34 & Rendah & \multirow{2}{*}{2} & \multirow{2}{*}{$13,33 \%$} \\
\hline & 34 & Rendah & & \\
\hline \multirow{2}{*}{ Finishing } & 37 & Rendah & \multirow{2}{*}{2} & \multirow{2}{*}{$13,33 \%$} \\
\hline & 39 & Rendah & & \\
\hline Total & & & 15 & $100 \%$ \\
\hline
\end{tabular}

Tabel 3. Distribusi Frekuensi Lokasi Keluhan Musculoskeletal Disorders pada Pekerja Rolling Mill di PT Ispat Indo Sidoarjo

\begin{tabular}{lcccc}
\hline Lokasi keluhan MSDs & Jumlah Keluhan Agak Sakit & Persentase & Jumlah Keluhan Sakit & Persentase \\
\hline Leher atas & 9 & $60 \%$ & 2 & $13,3 \%$ \\
\hline Leher bawah & 8 & $53,3 \%$ & 3 & $20 \%$ \\
\hline Bahu kiri & 11 & $73,3 \%$ & & \\
\hline Bahu kanan & 12 & $80 \%$ & & \\
\hline Lengan atas kiri & 11 & $73,3 \%$ & & $40 \%$ \\
\hline Punggung & 4 & $26,7 \%$ & 6 & $6,7 \%$ \\
\hline Lengan atas kanan & 11 & $73,3 \%$ & 1 & $46,7 \%$ \\
\hline Pinggang & 6 & $40 \%$ & 7 & \\
\hline Bokong & & & & \\
\hline Pantat & & & & $33,3 \%$ \\
\hline Siku kiri & 2 & $13,3 \%$ & 5 & $33,3 \%$ \\
\hline Siku kanan & 2 & $13,3 \%$ & 5 & $20 \%$ \\
\hline Lengan bawah kiri & 7 & $46,7 \%$ & 3 & $20 \%$ \\
\hline Lengan bawah kanan & 7 & $46,7 \%$ & 3 & $6,7 \%$ \\
\hline Pergelangan tangan kiri & 8 & $53,3 \%$ & 1 & $20 \%$ \\
\hline Pergelangan tangan kanan & 8 & $53,3 \%$ & 3 & $6,7 \%$ \\
\hline Tangan kiri & 7 & $46,7 \%$ & & $6,7 \%$ \\
\hline Tangan kanan & 7 & $46,7 \%$ & 1 & \\
\hline Paha kiri & 8 & $53,3 \%$ & & \\
\hline Paha kanan & 8 & $53,3 \%$ & & \\
\hline Lutut kiri & 7 & $46,7 \%$ & & \\
\hline
\end{tabular}




\begin{tabular}{lcccc}
\hline Lokasi keluhan MSDs & Jumlah Keluhan Agak Sakit & Persentase & Jumlah Keluhan Sakit & Persentase \\
\hline Lutut kanan & 7 & $46,7 \%$ & 1 & $6,7 \%$ \\
\hline Betis kiri & 11 & $73,3 \%$ & 2 & $13,3 \%$ \\
\hline Betis kanan & 11 & $73,3 \%$ & 2 & $13,3 \%$ \\
\hline Pergelangan kaki kiri & 8 & $53,3 \%$ & & \\
\hline Pergelangan kaki kanan & 8 & $53,3 \%$ & & \\
\hline Kaki kiri & 7 & $46,7 \%$ & & \\
\hline Kaki kanan & 7 & $46,7 \%$ & & \\
\hline
\end{tabular}

tidaknya keluhan musculoskeletal dan tingkat keluhannya.

Identifikasi keluhan Musculoskeletal disorders berdasarkan tingkat keluhan yang dirasakan menurut Nordic Body Map (NBM). Berdasarkan metode NBM maka tingkat keluhan yang dirasakan dapat dikategorikan menjadi rendah, sedang, tinggi dan sangat tinggi.

Pada Tabel 2 tersebut dapat dilihat bahwa sebagian besar pekerja memiliki tingkat keluhan musculoskeletal sedang yaitu sebanyak 11 orang (73,34\%), yaitu pada Billet Reheating Furnace (BRF) dan Mill Equipment Area.

Pada Tabel 3 dapat dilihat bahwa lokasi keluhan musculoskeletal paling banyak pada para pekerja di PT Ispat Indo bagian Rolling Mill dengan mengeluh sakit yaitu pada pinggang sebanyak 7 orang $(46,7 \%)$, dan pekerja dengan mengeluh sakit yaitu pada punggung sebanyak 6 orang (40\%), serta agak sakit pada bahu kanan sebanyak 12 pekerja (80\%).

\section{Postur Kerja dengan Keluhan Musculoskeletal Disorders (MSDs)}

Hasil uji korelasi spearman antara postur kerja dengan keluhan musculoskeletal disorders (MSDs) di PT Ispat Indo Sidoarjo yang telah dilakukan, didapatkan nilai koefisien korelasi (r) spearman sebesar 0,770 yang artinya ada hubungan yang sangat kuat antara postur kerja dengan keluhan musculoskeletal disorders (MSDs).

\section{PEMBAHASAN}

\section{Postur Kerja}

Pengukuran postur kerja pada bagian Rolling Mill di PT Ispat Indo Sidoarjo menunjukkan bahwa sebanyak 11 orang pekerja $(73,34 \%)$ memiliki risiko tinggi dalam pekerjaannya. Menurut Tarwaka (2010), berdasarkan metode REBA apabila skor akhir dengan tingkat risiko kategori sangat tinggi maka diperlukan tindakan sesegera mungkin.
Hasil ini diperoleh karena setiap pekerja, apalagi yang masih memakai prinsip manual handling, seperti pada proses maintenance di PT Ispat Indo memiliki faktor risiko yang dapat menyebabkan Musculoskeletal Disorders (MSDs). Faktor risiko yang kerap menjadi penyebab terjadinya keluhan Musculoskeletal Disorders (MSDs) antara lain postur tubuh yang janggal, kerja statis dan gerakan repetitive (Dinardi dalam Nurhikmah, 2011) yang banyak ditemukan di area BRF dan Mill Equipment. Hal ini sama seperti yang diungkapkan oleh Mahardika (2014), bahwa postur kerja yang salah saat bekerja menunjukkan bukti yang kuat sebagai faktor yang dapat berkontribusi terhadap adanya keluhan Musculoskeletal Disorders (MSDs). Hasil keluhan yang didapat adalah leher pegalpegal, punggung nyeri, bahu pegal, tangan pegal, lutut nyeri, kaki kesemutan, di mana keluhan tersebut terjadi akibat pekerjaan posisi jongkok, membungkuk, leher menekuk, mengangkat, dan memukul yang dikerjakan secara monoton dan berulang-ulang.

Postur tubuh saat bekerja seharusnya dengan postur kerja yang ergonomi atau postur kerja yang alamiah, di mana didalam proses bekerja harus disesuaikan dengan anatomi tubuh agar tidak terjadi penekanan atau pergeseran pada bagian penting tubuh seperti tendon dan tulang, syaraf dan organ tubuh. Sehingga keadaan pekerja menjadi relaks dan tidak menyebabkan keluhan musculoskeletal dan sistem tubuh yang lain.

\section{Keluhan Musculoskeletal Disorders (MSDs)}

Bukhori (2010), menyebutkan bahwa Musculoskeletal Disorders (MSDs) atau gangguan otot skeletal yaitu adanya suatu gangguan atau gejala yang ada kaitannya dengan jaringan otot, ligamen, kartilago, sistem syaraf, tendon, pembuluh darah dan struktur tulang. Gejala awal pada musculoskeletal menyebabkan adanya rasa nyeri, sakit, kesemutan, 
mati rasa, kekakuan, bengkak, rasa terbakar, gemetar dan adanya gangguan tidur.

Pengukuran musculoskeletal disorders pada bagian Rolling Mill di PT Ispat Indo Sidoarjo menunjukkan bahwa sebanyak 11 pekerja $(73,34 \%)$ dari kelompok yang mengalami keluhan musculoskeletal tersebut termasuk ke dalam keluhan musculoskeletal kategori sedang. Menurut Tarwaka (2010), tingkat risiko kategori sedang memerlukan adanya tindakan di kemudian hari. Sedangkan berdasarkan lokasinya keluhan pada bagian tubuh yang dirasakan oleh pekerja di bagian Rolling Mill yaitu mengeluh sakit yaitu pada pinggang sebanyak 7 orang $(46,7 \%)$, dan pekerja dengan mengeluh sakit yaitu pada punggung sebanyak 6 orang $(40 \%)$, serta agak sakit pada bahu kanan sebanyak 12 pekerja $(80 \%)$.

Pada penelitian ini membuktikan bahwa kejadian keluhan MSDs disebabkan oleh postur kerja yang tidak baik atau tidak ergonomi dan beban kerja fisik. Selain itu kejadian MSDs mungkin saja bisa terjadi dikarenakan banyak faktor, misalnya dari faktor pekerja yaitu waktu kerja, usia pekerja yang semakin lama pekerja bekerja dan usia semakin tua, semakin besar faktor yang menyebabkan terjadinya MSDs, dan banyak faktor lainnya.

Kelemahan dari pengukuran ini bersifat subyektif, sebaiknya untuk mengetahui tingkat keluhan musculoskeletal tersebut dapat ditunjang dengan pemeriksaan medis dan hasil laboratorium dari dokter ahli atau fisioterapis, sehingga hasil yang didapat nanti lebih akurat.

\section{Postur Kerja dengan Musculoskeletal Disorders (MSDs)}

Pada proses pengangkatan alat di bagian Rolling Mill, faktor risiko pekerjaan yang dapat menyebabkan keluhan musculoskeletal adalah postur janggal, beban objek 10-25 kg, serta jenis pegangan yang jelek. Pada saat proses pengangkatan barang posisi punggung para pekerja cenderung membungkuk ketika mengangkat beban antara 10-25 kg, selain itu alat atau beban yang diangkat juga tidak memiliki pegangan sehingga dapat menyebabkan terjadinya keluhan musculoskeletal. Dalam penelitiannya Nurhikmah (2010) mengutip teori dari Levy dan Wegman (2000), yang menyatakan bahwa pekerja yang melakukan aktivitas mengangkat barang yang berat memiliki kesempatan 8 kali lebih besar untuk mengalami low back pain dibandingkan pekerja yang bekerja statis. Penelitian lain membuktikan bahwa hernia diskus lebih sering terjadi pada pekerja yang mengangkat barang berat dengan postur membungkuk dan berputar (Levy dan Wegman, 2000). Sehingga bila beban yang hendak diangkat tersebut terlalu berat, diharapkan agar para pekerja meminta bantuan temannya untuk mengangkat barang tersebut untuk menghindari terjadinya cidera pada otot punggung.

Berdasarkan hasil uji korelasi spearman antara postur kerja dengan keluhan musculoskeletal disorders (MSDs) yang telah dilakukan, didapatkan nilai koefisien korelasi (r) spearman sebesar 0,770 yang artinya ada hubungan yang sangat kuat antara postur kerja dengan keluhan musculoskeletal disorders (MSDs). Hal tersebut sesuai dengan studi yang dilakukan European Campaign On musculoskeletal disorders pada tahun 2008 terhadap 235 juta orang pekerja di Eropa, dilaporkan bahwa $62 \%$ mengalami keluhan MSDs pada tangan akibat adanya gerakan repetitive atau berulang dan $46 \%$ dilaporkan akibat postur tubuh yang melelahkan selama bekerja.

Kegiatan aktivitas fisik (mengangkut, memasukkan dan mengeluarkan) cucian dari mesin cuci menyebabkan nyeri di punggung pada pekerja laundry. Postur terbentuk pada saat melakukan mengangkut, memasukkan dan mengeluarkan cucian yang berbeda-beda dan umumnya cenderung melakukan postur kerja yang menjauhi sikap alamiah tubuh yang dampaknya menyebabkan terjadinya keluhan Musculoskeletal Disorders. Pada pekerjaan laundry, pekerja bagian pencucian berada dalam postur statis pada tubuh bagian bawah dan mengalami gerakan berulang (repetitif) pada bagian tangan. Pada saat tubuh berada dalam posisi statis, akan terjadi penyumbatan aliran darah dan mengakibatkan pada bagian tersebut kekurangan oksigen dan glukosa dari darah. Tubuh juga akan menghasilkan sisa metabolisme seperti asam laktat yang tidak diangkut keluar akibat peredaran darah yang terganggu sehingga menumpuk dan menimbulkan rasa nyeri (Ulfah, 2014).

Postur tubuh pekerja saat mengangkat barang yang cenderung sering membungkuk ke depan dapat menyebabkan tertariknya otot sehingga menyebabkan timbulnya keluhan musculoskeletal. Lokasi yang biasanya sering dikeluhkan oleh para pekerja adalah sekitar pinggang $(46,7 \%)$ dan punggung (40\%). Pinggang merupakan bagian tubuh manusia yang rentan karena di dalam mekanisme tubuh, pinggang berperan sebagai titik tumpu yang mendapatkan tekanan terbesar dalam struktur tulang belakang. Berat beban yang diangkat dan 
jarak ke depan dari tubuh saat barang diangkat mempengaruhi besar tekanan yang diberikan pada titik tumpu tubuh.

Sikap kerja tidak ergonomi atau tidak alamiah membuat posisi bagian-bagian tubuh beraktivitas atau bergerak menjauhi posisi alamiah, misalnya yaitu kepala terangkat, punggung terlalu membungkuk serta pergerakan tangan terangkat ke atas. Postur tubuh yang tidak alamiah (tidak stabil) tersebut menunjukkan bukti yang kuat sebagai faktor yang dapat menyebabkan terjadinya MSDs dan menimbulkan terjadinya keluhan pada punggung, pinggang, dan tangan (Tanjung, 2015). Kurnianto (2013), menerangkan bahwa delapan dari tiga belas total pekerja welding dengan postur kerja posisi punggung membungkuk, posisi lengan di bawah bahu dan duduk berpotensi mengalami kerusakan pada sistem musculoskeletal.

Bagi pekerja, adanya kegiatan pengangkatan beban merupakan suatu kegiatan yang sangat bermakna karena dapat dijadikan sebagai salah satu pekerjaan yang dapat meningkatkan penghasilan ekonomi. Padahal, perlu diwaspadai bahwa setiap pekerjaan pasti memiliki tingkat risiko yang sangat berbeda. Demikian halnya pada pekerjaan pengangkatan barang atau kegiatan manual memiliki kecenderungan risiko dapat mengalami gangguan atau keluhan pada tulang dan otot, dan apabila risiko tersebut tidak diimbangi dengan teknik-teknik pencegahan yang sesuai, maka akan menyebabkan dampak yang apabila terus dihiraukan akan menjadi suatu bahaya yang lebih besar lagi seperti terjadinya cidera yang menumpuk dan kerusakan pada sistem musculoskeletal.

Agar risiko pekerjaan yang dihadapi tidak menjadi semakin besar, sebaiknya dari perusahaan memberikan pelatihan khusus terkait prosedur manual handling atau pengangkutan beban yang baik dan benar kepada pekerja lama atau pekerja baru, serta melakukan suatu pengawasan rutin guna memantau program yang telah dicanangkan sehingga pekerja tidak lagi melakukan kegiatan pengangkutan dengan membentuk postur kerja tidak alamiah yang cenderung seenaknya. Suma'mur (2009), menerangkan bahwa cara mengangkat dan mengangkut yang baik harus memenuhi dua prinsip yaitu momentum gerak badan dimanfaatkan untuk mengakali gerakan serta beban diusahakan menekan pada otot tungkai yang kuat dan sebanyak mungkin otot tulang belakang yang lebih lemas dibebaskan dari pembebanan.
Pedoman bagi pekerja untuk aktivitas angkat angkut yang aman menurut Tarwaka (2010), Hal-hal yang harus dipertimbangkan bagi pekerja agar setiap aktivitas angkat dapat dilakukan secara lebih aman, antara lain meliputi hal-hal sebagai berikut: pertama perlu dilakukan pengecekan label pada kontainer atau pembungkus beban/objek. Kedua, sebelum mengangkat, selalu lakukan pengetesan terhadap beban untuk stabilitas dan berat beban. Ketiga, untuk beban yang tidak stabil dan atau berat, ikuti pedoman untuk manajemen. Keempat, harus ada rencana angkat yang tetap, yaitu: gunakan sepatu kerja yang tepat untuk menghindarkan kemungkinan terselip, terpeleset atau terjatuh. Angkat hanya semampu yang dapat dikerjakan dengan aman tanpa kemungkinan terjadi risiko cidera. Upayakan mengangkat pada power zone, yaitu di atas titik pertengahan paha, di bawah bahu dan bawa sedekat mungkin dengan badan, jika memungkinkan. Harus dengan ekstra hati-hati pada saat mengangkat beban yang tidak stabil, dan jika harus menggunakan sarung tangan, maka pilih ukurannya yang betul-betul tepat. Kelima, jika pekerja harus mengangkat secara langsung dari lantai, hindarkan posisi pinggang membungkuk, namun demikian perlu diperhatikan, bahwa teknik ini hanya akan efektif jika beban yang diangkat adalah ukurannya kecil, beratnya ringan dan beban dengan mudah diapit di antara kedua lutut. Keenam, pada saat mengangkat beban, perlu diperhatikan hal-hal sebagai berikut: pastikan dapat memegang objek dengan aman, selalu gunakan kedua tangan jika memungkinkan, hindarkan mengangkat secara mendadak dan lakukan secara perlahan-lahan atau tanpa pengerahan tenaga kejutan, upayakan objek sedekat mungkin dengan badan, gunakan kaki untuk mendorong ke atas dan mengangkat beban, dan bukan menggunakan tulang belakang sebagai tumpuhan mengangkat, hindarkan memuntirkan tubuh pada saat mengangkat dan memindahkan beban, serta istirahat secukupnya di antara periode waktu kerja.

Penulis atau peneliti setelah penelitian dilaksanakan, telah memberikan materi dan pelatihan kepada petugas atau pekerja bagian Rolling Mill di PT Ispat Indo Sidoarjo mengenai manual handling atau cara angkat angkut yang benar, ergonomi, musculoskeletal disorders serta cara untuk menghindari dan menanggulangi adanya keluhan pada Musculoskeletal Disorders. 


\section{SIMPULAN}

Sebagian besar postur kerja pekerja memiliki tingkat risiko (menggunakan metode REBA) dengan kategori sangat tinggi, sebagian besar pekerja mengalami keluhan Musculoskeletal Disorders dengan tingkat keluhan kategori sedang, dan faktor postur kerja mempunyai keeratan hubungan yang sangat kuat dengan kejadian keluhan musculoskeletal disorders.

Saran penelitian ini yaitu; instansi atau perusahaan dapat melakukan perbaikan layout pekerjaan dengan menghindarkan lantai bertingkat dengan cara meratakan lantai, sehingga dapat mengurangi terjadinya hal yang tidak diinginkan. Selain itu melakukan pengawasan rutin guna memantau program yang dicanangkan sehingga pekerja tidak lagi melakukan kegiatan pengangkutan dengan membentuk postur yang cenderung seenaknya. Membuat dan memberikan buku saku kepada setiap pekerja yang berisi tentang keselamatan dan kesehatan kerja, khususnya berisi tentang bahaya dan risiko postur kerja yang tidak alamiah, serta mengadakan secara rutin kegiatan olah raga satu kali dalam seminggu selama 30-45 menit di perusahaan, untuk meningkatkan kesegaran fisik para pekerja sehingga dapat mengurangi terjadinya keluhan musculoskeletal.

\section{DAFTAR PUSTAKA}

Asni. 2014. Hubungan Risiko Postur Kerja dengan Keluhan Musculoskeletal Disorders (MSDs) pada Pemanen Kelapa Sawit di PT Sinergi Perkebunan Nusantara. Skripsi. Kesehatan dan Keselamatan Kerja Fakultas Kesehatan Masyarakat UNHAS Makasar.

Bukhori, E. 2010. Hubungan Faktor Risiko Pekerjaan dengan Trjadinya Keluhan Musculoskeletal Disorders (MSDs) pada Tukang Angkut Beban Penambang Emas di Kecamatan Cilugrang Kabupaten Lebak. Skripsi. Universitas Islam Negeri. Jakarta.

Cohen, A.L. 1997. Elements of Ergonomics Programs. A Primer Based on Workplace Evaluations of Musculoskeletal Disorders. Amerika; U.S Department of Health and Human Services. NIOSH.

Hendra., Rahardjo, Suwandi. 2009. Risiko Ergonomi dan Keluhan Musculoskeletal Disorders (MSDs) pada Pekerja Panen Kelapa Sawit. Jurnal Keselamatan dan Kesehatan Kerja-FKMUI, semarang, 17-18 November 2009: pp. 1-8.
International Labour Organization (ILO). 2013. The Prevention of Occupational Disease. Geneva; International Labour Organization.

Kurnianto, R., Mulyono. 2013. Gambaran Postur Kerja dan Resiko Terjadinya Muskuloskeletal pada Pekerja Bagian Welding di Area Workshop Bay 4.2 PT. Alstom Power Energy Systems.The Indonesian Journal of Occupational Safety, Health and Environment, Vol. 1, No. 1 Jan-April 2014: pp. 61-72. Tersedia di: http://journal.unair. ac.id/download-fullpapers-kklkf81f1 0362f2full. pdf [diakses tanggal 30 Januari 2017].

Levy, B., Wegman, D. 2000. Occupational Health: Recognizing and Preventing Work-Related Disease and Injury, Fourth Edition. Philadelpia; Lippincott Williams and Wilkins.

Mahardika, Tanjung. 2014. Perancangan Fasilitas Kerja untuk mengurangi Keluhan Musculoskeletal Disorders (MSDs) dengan Metode Rapid Entire Body Assessment pada Pekerja Pembuatan Paving dan Batako pada UKM Usaha Baru. [e-jurnal] 6858 Volume 9, No.2, Mei 2014. Pp. 1-8 Tersedia di: www.ejournal.undip.ac.id/index.php/jgti/ article/view/6858 [Diakses tanggal 29 Januari 2017].

Nurhikmah. 2011. Faktor-faktor yang Berhubungan dengan Musculoskeletal disorders (MSDs) pada Pekerja Furniture di kecamatan Benda Kota Tangerang. Skripsi. Jakarta; UIN.

Puskesmas Rumbio Jaya. 2011. Laporan UKK (Usaha Kesehatan Kerja) bulan Maret. Profil Puskesmas Rumbio Jaya.

Putri, AS., Saftarina, F., Wintoko. R. 2013. Hubungan Masa Kerja dan Posisi Kerja dengan Kejadian Low Back Pain (LBP) pada Pekerja Pembersih Kulit Bawang di Unit Dagang (UD) Bawang Lanang Kelurahan Iringmulyo Kota Metro. Faculty of Medicine of Lampung University, ISSN 23373776: pp. 1-7. Tersedia di: http://jukeunila.com/ wpcontent/uploads/2016/05/5-Amelia-Sagita.pdf [Diakses tanggal 29 Januari 2017].

Suma'mur. 2009. Higiene Perusahaan dan Kesehatan Kerja (Hiperkes). Jakarta; CV Sagung Seto.

Sumiati. 2007. Analisis Risiko Low Back Pain (LBP) pada Perawat Unit Darurat dan Ruang Operasi di RS Prikasih Jakarta Selatan. Skripsi. Fakultas Kesehatan Masyarakat. Universitas Indonesia.

Tanjung, S. 2015. Analisis Postur Kerja Menggunakan Metode Rula untuk Mengurangi Risiko Musculoskeletal Disorders (Studi Kasus pada Pekerja di Plant KT-24. PT Bakrie Pipe Industries). Jurnal Ilmiah Universitas Bakrie, 
Volume: 3, No.02 (2015). Tersedia di: www. journal.bakrie.ac.id/index.php/jurnal_ub/article/ view/947 [diakses tanggal 29 Januari 2014].

Tarwaka, Bakri, SHA., Sudiajeng, L. 2004. Ergonomi untuk Keselamatan, Kesehatan Kerja dan Produktivitas. UNIBA Press: Surakarta.
Tarwaka. 2010. Ergonomi Industri. Surakarta; Harapan Press Solo.

Ulfah, Nur., Harwanti, S., Nurcahyo, P. J. 2014. Sikap Kerja dan Risiko Musculoskeletal Disorders pada Pekerja Loundry. Jurnal Kesehatan Masyarakat Nasional, Volume 8, No. 7 Februari 2014: pp. 313-318. 